\title{
Psychiatric Rehabilitation
}

\author{
A lack of direction \\ J. M. Dingwall, Consultant Psychiatrist, Dykebar Hospital, Paisley, Scotland
}

According to the recent Commons Report on Community Care, ${ }^{1}$ psychiatric patients are being discharged to inadequate community care. One of the reasons given for this situation is the lack of communication between professional groups, leading to bad planning of care.

This poor communication would seem to exist not only between health service and local authority planners but also between individual health boards and hospitals. Since the middle of the 1950s psychiatric rehabilitation has become more active and organised. However, 30 years on there would still seem to be little in the way of central planning and co-ordination.

Many psychiatric hospitals in Scotland now have an area designated for rehabilitation. After patients are fully assessed in these areas their individual needs are noted, goals are set and programmes organised to help achieve these goals. With appropriate patients, where preparation is being made for discharge, these programmes often include social skills training and the learning or re-learning of everyday living skills. Often the patient will have the opportunity to live in the hospital but as independently as possible by the allocation of a self-care allowance. This is a sum of money provided by the hospital to the patient allowing him to purchase food and everyday living materials such as soap, washing-up liquid, toilet rolls, etc. The hospital's costs are to some extent offset by no longer having to provide these materials for the patient. Also, many hospitals provide a rehabilitation or socialisation allowance, which again is a sum of money provided by the hospital allowing rehabilitation programmes to include social skills training in a realistic setting, i.e. the community. Such an allowance also enables patients not in receipt of a self-care allowance to buy and prepare some foodstuffs as a step towards self-care.

In the author's own hospital, a self-care allowance of £8.50 per person per week for between four and six patients was allocated in 1981. Over the next few years a multidisciplinary rehabilitation team was set up and various changes made, allowing a full rehabilitation programme to take place. Despite this and several requests for increased funding, by February 1984 the self-care allowance remained the same and there was no provision for a socialisation allowance. There are no guidelines as to how much these allowances should be - but it was felt that $£ 8.50$ was rather a small sum to try to buy a week's food, never mind other materials. It was also known that other rehabilitation units in Scotland were in receipt of differing amounts of monies for these allowances. It was decided to contact these other units and to compare the differing figures in an attempt to strengthen the team's case before yet another request to the administration.

\section{Method}

A previous study of 'new chronic' psychiatric patients had been carried out in several Scottish psychiatric hospitals. ${ }^{2}$ It was known that these hospitals had some form of rehabilitation set-up and it was felt that the consultants in these units would be most likely to reply to the present survey. One other hospital which was about to set up a rehabilitation unit was also included.

The consultants involved in these hospitals were contacted by letter in Spring 1984 and asked what amounts, if any, their rehabilitation units received for a self-care allowance and for socialisation and also for how many patients the amounts catered. If a consultant did not respond he was, where possible, contacted by telephone. A follow-up contact with the responding consultants was made a year later allowing them to check their entry in the results and asking for comments.

\section{Results}

It was obvious that different hospitals had different types of rehabilitation set-ups and used different terms for any monies received. The author has used the terms described above for the results table. In the follow-up contact none of the consultants disagreed with their entry nor the terms used. Fifteen units, including the author's own hospital, were contacted. Replies were received from nine consultants, two clinical psychologists and one nursing officer. In at least two cases, the consultants had obtained the information from hospital administrators. A table was drawn up from these twelve hospitals which were from eight Health Boards.

In the year between initial contact and follow-up, the only increases in these figures indicated to the author were that one hospital-Craig Dunain-had obtained $f 1000$ per year as a socialisation fund and had managed to obtain increased DHSS payments to in-patients; the author's own team at Dykebar had obtained $£ 1050$ per year for the rehabilitation ward, i.e. about $£ 2$ per week per patient, and $£ 450$ per year for a hostel ward as a socialisation allowance.

Although the twelve hospitals may not be truly representative of all Scottish psychiatric hospitals, their total catchment area population is just over 2.3 million or approximately $46 \%$ of the Scottish population. The most striking point from the table is the wide differences between the units. This does not reflect any differences in specific Health Board policies as the results from hospitals within the same Health Board also differ greatly. It must be concluded that the table reflects individual hospital arrangements. 
TABLE

Rehabilitation allowances per head per week unless otherwise stated at Spring 1984

\begin{tabular}{|c|c|c|c|c|}
\hline Hospital & Health Board & Socialisation & Self-care & Total \\
\hline Crichton Royal, Dumfries & Dumfries \& Galloway & $£ 4.50$ & $£ 16$ & $£ 20.50$ \\
\hline Gartnavel Royal Hospital* & Greater Glasgow & £5 & £15 & $£ 20$ \\
\hline Bangour Village Hospital & Lothian & £5 + travelling expenses & $£ 11$ & $£ 16+$ \\
\hline $\begin{array}{l}\text { Ailsa Hospital, Ayr } \\
\text { Leverndale Hospital, }\end{array}$ & Ayrshire \& Arran & Expenses & $£ 14$ & fl4t \\
\hline Glasgow & Greater Glasgow & $£ 2$ & $£ 10$ & $£ 12$ \\
\hline Sunnyside, Montrose & Tayside & $\begin{array}{c}£ 480 / \text { year } \\
\text { (average } 40 \text { patients) }\end{array}$ & $\begin{array}{c}£ 8.90 \\
(+£ 5.40 \mathrm{IT} \text { incentive })\end{array}$ & f11.40+ \\
\hline Dingleton Hospital & Borders & 0 & $\begin{array}{c}\text { fll.20 } \\
(+ \text { tea, cofice, sugar and squash } \\
\text { from hospital) }\end{array}$ & f11.20+ \\
\hline Craig Dunain, Inverness & Highlands & 0 & 69 & E9 \\
\hline Gartloch Hospital, Glasgow & Greater Glasgow & $\begin{array}{l}£ 20 \text { for average } 12 \text { patients } \\
\text { (average } £ 1.66 / \text { head) } \\
+£ 10 / \text { week to hostel ward }\end{array}$ & f7.80 & $£ 8.66$ \\
\hline Dykebar Hospital, Paisley & Argyll \& Clyde & 0 & $£ 8.50$ & $£ 8.50$ \\
\hline Murray Royal, Perth & Tayside & $£ 25 /$ year & E5 (for weekends only) & $\mathfrak{f 5 +}$ \\
\hline Ravenscraig, Greenock & Argyll \& Clyde & $£ 3.50$ & 0 & $£ 3.50$ \\
\hline
\end{tabular}

-Proposed unit.

\section{Discussion}

The fact that information was obtained from non-medical colleagues in almost half the hospitals in the study may indicate that it is not always a psychiatrist who is most involved in the organisation of rehabilitation units. Robinson, ${ }^{3}$ after visiting several such units, was in no doubt that rehabilitation worked best on a multi-disciplinary basis. What role the consultant should play in this set-up is open to debate. Clark ${ }^{4}$ has suggested that the doctor should be an 'administrative therapist' whilst in A Handbook of Psychiatric Rehabilitation Practice Wings suggests that one consultant in each district should assume special responsibility for planning, co-ordination and management of rehabilitation. It seems that hospitals make their own arrangements but Wing's suggestion is the most likely to lead to a well-organised unit. It may mean a blurring of role but if taken up by Health Boards when making appointments it should result in at least a degree of consistency and the base from which future co-ordinated planning can stem.

A more interesting point is that although this paper has looked at only one small aspect of the organisation of rehabilitation units in psychiatric hospitals, it is one which is basic to the running of such units. The fact that all the hospitals in the table had some form of payment indicated general acceptance of the requirement for such funding. And yet, given that acceptance, how can it be that there is a six-fold difference between the top and bottom of the table? McCreadie et $\mathbf{a l},{ }^{6}$ looking at rehabilitation facilities in Scottish psychiatric hospitals in much more detail, also found large differences between hospital facilities provided.
In the same paper, it is stated that the targets set by DHSS for NHS hospital-based developments are largely being met in Scotland, but one wonders if this is by accident or design. Looking at the above table showing hospital difference and that of McCreadie et al, it would appear to be the former. There seems to be a lack of a central policy, or at least, a lack of communication between the policy makers and the people who are actually doing the work. The concept of community care has been accepted by political parties and governments of all colours and yet there is still a lack of political will to transform the concept into a working reality.

Most of the current criticism of community care projects is directed at the local authority's failure to provide appropriate facilities. It is easy to criticise these authorities, especially with regard to facilities for occupation, but are we in the Health Service any better organised, or is any progress due to keen and able individuals-not always medical-in individual hospital units where there is a receptive and responsive administrative set-up? There is a great risk of complacency if we feel that we are doing our bit and that the local authorities are preventing progress. In an attempt to co-ordinate policy and exert pressure on the administration, it was felt that staff from various units should meet regularly to discuss the practical problems in organising and running a rehabilitation unit. When the responding consultants in the survey were asked about this at follow-up, only one felt there was no need for such meetings. Others felt that the meetings could be incorporated into the meetings of the Group for the Study of Rehabili- 
tation and Community Care of the Scottish Division of the Royal College of Psychiatrists. All those in favour of meetings emphasised that if they were to be useful, the meetings would require to be multi-disciplinary. Each psychiatric hospital in Scotland was then contacted and an inaugural meeting was held at Dykebar Hospital, Paisley, in April 1986. This was attended by 98 people from 16 different psychiatric hospitals. More recently a second meeting was held at Ailsa Hospital in Ayr. Further meetings are organised up until Spring 1988 and a Committee has been formed to attempt to achieve the above objectives. Perhaps, with such a positive response, this is the way forwardformulating our own policy and finding our own direction.
REFERENCES

${ }^{1}$ House of Comanons Social Services Comamtee (1985) Second Report from the Session 1984/85-Community Care, Vol. 1. London: HMSO.

2McCreade, R. G., Wilson, A. O. \& Burton, L. L. (1983) The Scottish survey of new chronic in-patients. British Journal of Psychiatry, 143, 569-572.

${ }^{3}$ Rosinson, A. J. (1982) A clinical attachment in rehabilitation. Bulletin of the Royal College of Psychiatrists, 6, 197-199.

4Clark, D. H. (1964) Administrative Therapy. London: Tavistock.

${ }^{5}$ WING, J. K. \& Morrs, B. (1981) Handbook of Psychiatric Rehabilitation Practice. Oxford University Press, p. 15.

6MCCreade, R. G., Affleck, J. W. \& Robnson, A. D. (1985) The Scottish survey of psychiatric rehabilitation and support services. British Journal of Psychiatry, 147, 289-294.

\section{Infant Psychiatry}

\section{Recent developments}

DE Wet Vorster, Consultant Child and Family Psychiatrist, Nuffield Clinic, Plymouth

Infant psychiatry research pursued over the last two years was presented at the International Conference of the Association of Child Psychology and Psychiatry and Allied Disciplines in Paris, July 1986, and the value of early intervention was underlined at the Third World Congress of Infant Psychiatry, Stockholm, August 1986.

With regard to early intervention, state financial help is given in Sweden for families from fairly early on in pregnancy until infants reach two years of age, and the value of primary care workers having regular contact at health centres with psychologists and other members of the child psychiatry team was presented. At district centres, children with special difficulties are catered for in group situations together with parents.

Dr John Bowlby presented an overview at the Paris conference, describing the "analyst without the couch". He indicated the dovetailing of some analytic concepts with observational interactional relationships between mother, father, infant, describing the "good enough" mother's sensitivity to the infant's signals. She is not intrusive, but "reliable and available". He considered infants socially responsive from birth.

Dr D. Anzieu, Professor of Psychology, Paris University, read a paper entitled 'Ego Skin' relating the vital importance of the skin both as "container" and also "stimulator". The ego was "the psychic skin". He described the difference between touch, and visual and auditory perceptions considering skin a "boundary" organ, transmitting the mutual sensation of life rhythms to both partners. He mentioned the analytic "object or part object" as not primarily the breast that feeds but encompassing the skin, the whole per- son, reminiscent of the womb (containment). He considered autistic phenomena might occur, as he had found in clinical practice, as a result of a specially traumatic event distressing mother to the extent that at a specific time she failed to experience pleasure in interaction with her infant; this was not her "fault". He described the difficulty the infant has in moving from the fantasy of a common skin with his mother to his own skin as a border and a container.

Dr J. Kennell, paediatrician, and researcher, Cleveland, USA, described the development of "fathers' maternity visitation" in the last few years; only $17 \%$ were present at the delivery in 1973 whereas now, $75 \%$ of fathers in the USA attend the delivery of their babies.

He described research in Guatemala where the addition of the "Doula" to the maternity plans resulted in decreased need for the special care baby unit, decreased Caesarian rate and other advantages. The "Doula" is a type of mother's helper who, having had children herself, and with some training, gets to know the mother towards the end of her pregnancy and is there throughout the labour. The mother was more likely to be awake after birth than mothers in the control group. Fathers were more involved. The helper was present to guide mother throughout the birth process. The "Doula" concept was now being pursued in the USA: contrast the unfortunate rush in some of our maternity wards where there is not continuity of staff.

Dr N. Ringler described her follow-up of the babies in Cleveland, USA, who were allowed extra proximity with their mothers immediately postbirth to eight years of age. These children continue to have a better ability to share emotions, more positive interactional relationships with 